\title{
Plantas nativas e a prática da contextualização: uma investigação etnobotânica no ensino de ciências
}

\author{
Native plants and the practice of contextualization: an ethnobotanical \\ investigation in science teaching
Plantas nativas y la práctica de la contextualización: una investigación etnobotánica en la enseñanza de las ciências

\author{
Bruno Ferreira Matos (brunomatos1996@ hotmail.com) \\ Universidade Estadual do Ceará (FAEC/UECE).
}

José Jucelino Alves de Souza (josejucelino2012@hotmail.com) Universidade Estadual do Ceará (FAEC/UECE).

Rafaela Vieira Façanha (rafaelavieiraf@ gmail.com)

Faculdade Ieducare.

Francisco Nunes de Sousa Moura (nunes.moura@alu.ufc.br) Universidade Estadual do Ceará (FAEC/UECE)

Deborah Ximenes Torres Holanda (dedeximenes@ hotmail.com)

Universidade Estadual do Ceará (FAEC/UECE)

Resumo: O presente trabalho tem como objetivo realizar um estudo etnobotânico sobre plantas nativas, com foco em três espécies vegetais, e fazer um paralelo entre o que a ciência diz sobre tais espécies com o conhecimento que uma comunidade escolar detém sobre elas, promovendo conexões para a contextualização no ensino de ciências. Para isso, foram selecionadas três espécies nativas da cidade de Ipaporanga-CE para identificação e estudo. Posteriormente, foi aplicado um questionário com alunos, professores e funcionários de uma escola a fim de obter informações sobre essas espécies vegetais e, assim, realizar uma comparação de dados. Por fim, foi realizado um seminário na escola pesquisada para construir com alunos e professor o conhecimento sobre as características, propriedades e utilizações desses frutos nativos, objetivando tornar estas espécies mais conhecidas, aproveitadas e dando pistas de contextualização de conteúdos nas aulas de ciências. Constatou-se que o público escolar reconhece algumas plantas vegetais nativas, porém, no que diz respeito às propriedades e benefícios, possuem pouco conhecimento.

Palavras-chave: Etnobotânica; Contextualização; Ensino de Ciências.

Abstract: This work aims to carry out an ethnobotanical study on native plants, focusing on
three plant species, and to make a parallel between what science says about such species with
the knowledge that a school community has about them, promoting connections for
contextualization in science education. For this, three species native to the city of Ipaporanga-
CE were selected for identification and study. Subsequently, a questionnaire was applied to
students, teachers and school staff in order to obtain information about these plant species and

Recebido em: $27 / 01 / 2021$

Aceite em: 20/08/2021 
thus carry out a data comparison. Finally, a seminar was held at the researched school to build knowledge with students and teacher about the characteristics, properties and uses of these native fruits, aiming to make these species better known, used and giving clues to contextualize content in science classes. It was found that the school audience, recognizes some native plant plants, however with regard to properties and benefits they have little knowledge.

Keywords: Ethnobotany; Contextualization; Science teaching.

Resumen: Este trabajo tiene como objetivo realizar un estudio etnobotánico sobre plantas nativas, enfocándose en tres especies vegetales, y hacer un paralelo entre lo que la ciencia dice sobre dichas especies con el conocimiento que una comunidad escolar tiene sobre ellas, promoviendo conexiones para la contextualización en la educación científica. Para ello, se seleccionaron tres especies nativas de la ciudad de Ipaporanga-CE para su identificación y estudio. Posteriormente, se aplicó un cuestionario a alumnos, docentes y personal escolar con el fin de obtener información sobre estas especies vegetales y así realizar una comparación de datos. Finalmente, se realizó un seminario en la escuela investigada para construir conocimiento con alumnos y docente sobre las características, propiedades y usos de estos frutos nativos, con el objetivo de dar a conocer, utilizar y dar pistas para contextualizar contenidos en las clases de ciencias. Se encontró que el público escolar, reconoce algunas plantas vegetales nativas, sin embargo en cuanto a propiedades y beneficios tienen poco conocimiento.

Palabras-clave: Etnobotánica; Contextualización; Enseñanza de las ciencias.

\section{INTRODUÇÃO}

O uso das plantas, em diversas atividades do ser humano, acompanha a história da humanidade. Sociedades primitivas já utilizavam espécies vegetais para a alimentação, porém, ao longo do tempo, outras finalidades contribuíram para ampliar o conhecimento e a utilização destes recursos. Cada conhecimento era aprimorado para o uso no tratamento de enfermidades, assim como os processos de escolha, colheita e secagem eram vistos rigorosamente por tais povos. Outras finalidades também intensificaram o estudo de plantas, como a utilização para fins cosméticos (FREITAS et al., 2014).

A interação do ser humano com a diversidade vegetal, seja pelo potencial cultural ou econômico, constitui a etnobotânica. Essa ciência vem a se tornar um dos alicerces da vida de populações que podem utilizar-se das diversas finalidades ofertadas por essas espécies. Desta forma, pode-se conceituá-la como a relação do homem com a natureza, que engloba também as culturas e os saberes que contribuíram para a manutenção da biodiversidade e que, ao longo do tempo, nas sociedades e em seus ambientes permitiram um equilíbrio entre ambos (AGOSTINHO, 2016). 
Em meio à variedade de espécies vegetais, foi encontrado um grupo denominado "plantas nativas”. Esta denominação é empregada em espécies e frutos que já existiam no território brasileiro, antes mesmo da chegada dos colonizadores europeus ao Brasil. A grande maioria delas já era utilizada na alimentação dos povos indígenas que habitavam este país nesta época, fator esse que explica a razão da maioria dos nomes dessas plantas terem origem na língua tupi guarani (CETAP, 2015).

O Brasil, por possuir uma grande diversidade de espécies, constitui também um potencial frutífero ainda a ser explorado, podendo ser utilizado como matéria-prima para indústrias e como novas opções de frutos para o mercado. Isso vem aumentando cada vez mais por conta de fatores como sabor e aroma que acabam por se tornarem apreciados pela população (NEGRI; BERNI; BRAZACA, 2016). Complementarmente, também se observa a diversidade de culturas, comunidades e povos que há muitos séculos convivem em meio a essas espécies e, a partir dessa convivência, manejam essa biodiversidade (HANAZAKI, et al. 2018).

Para melhor valorização destas espécies, é preciso disseminar o conhecimento científico sobre elas em vários meios de alcance para todos, pois, apesar de a população conviver com as espécies vegetais, nota-se que muitos integrantes dela não possuem um conhecimento mais profundo a respeito dos benefícios e potencialidades culturais e mercadológicos que elas possuem. Por conta deste limitado conhecimento, em várias pesquisas, as frutas nativas são também denominadas de frutas não convencionais (KOHLER; BRACK, 2016).

Com isso, o ambiente escolar é um dos locais propícios para realizar essa disseminação de conhecimento dessas espécies nativas. Primeiro deve-se compreender essa relação do homem com as espécies vegetais em geral, o que leva à etnobotânica, e, por fim, estudar e analisar as características de espécies específicas. Estas análises e estudos precisam ser utilizados para enriquecer as aulas de ciências, tendo como outra vantagem a instrução desse conhecimento por intermédio das gerações mais novas.

$\mathrm{Na}$ perspectiva da falta de informações sobre as plantas nativas, é possível que as próximas gerações não tenham conhecimento sobre tais espécies, pois não há incentivos que contribuam para o seu melhor conhecimento e utilização. Além disso, quando se fala do ensino de botânica, o ambiente escolar ainda encontra dificuldades em contextualizar os saberes sobre essas espécies vegetais locais nas aulas de ciências, o que contribui para o desconhecimento do público escolar, bem como da população em geral, podendo culminar até no desaparecimento das espécies vegetais devido ao desconhecimento e à desvalorização das espécies nativas. 
No contexto escolar, muitas vezes, o professor é limitado apenas à utilização de exemplos e propostas que apostilas e livros didáticos trazem para a abordagem de certos assuntos, tendo ainda deficiência nas metodologias utilizadas na educação (CRUZ; JOAQUIM; FURLAN, 2011). No ensino de ciências, a metodologia ativa de aprendizagem, por exemplo, pode contornar essa situação, pois faz com que o aluno construa novos conhecimentos a partir da contextualização dos assuntos com a realidade, ou seja, de forma que o professor traga um problema vivenciado pelo aluno para dentro do âmbito escolar e o estimule a fazer novas investigações (NASCIMENTO; COUTINHO; 2017).

Uma metodologia eficiente na educação científica é a prática da investigação. Ao fim do processo educativo, torna-se necessário que o aluno esteja estimulado e naturalize o buscar, o pesquisar e o investigar, como uma forma de desenvolver interesse por determinado tema, tendo cautela durante a escolha dessas estratégias para construir um conhecimento científico eficaz (RODRIGUES; BORGES, 2008). Aliadas à metodologia adequada, é fundamental que as aulas de ciências sejam contextualizadas, pois, de acordo com Leite, Fernandes e Mouraz (2012), essa prática permite a aproximação da realidade dos alunos com a educação escolar, relacionando as atividades desenvolvidas em sala de aula com a vida, os saberes e a cultura do estudante.

Portanto, este artigo descreve uma investigação etnobotânica sobre os aspectos e as funcionalidades de espécies nativas, uma vez que temáticas como essa são necessárias para que se possa fazer um trabalho de disseminação dessas espécies. Essa proposta também culmina em aproximar a temática abordada dentro do contexto em que o aluno vive, permitindo assim uma contextualização durante as aulas de ciências. Adicionalmente, esse tipo de estudo pode promover ao aluno maior pertencimento e preservação do local do qual faz parte.

Diante do exposto, o trabalho tem como objetivo realizar um estudo etnobotânico sobre plantas nativas, a fim de verificar o grau de conhecimentos detidos por uma comunidade escolar - estudantes, funcionários e professores e a partir desse estudo contextualizar o assunto nas aulas de ciências do ensino fundamental II, com exemplos do cotidiano, de forma dialogada, como proposta de conhecimento, pertencimento e preservação do local em que vivem.

\section{METODOLOGIA}

A presente investigação consiste em uma pesquisa-ação sobre o conhecimento etnobotânico de sujeitos escolares, tendo uma abordagem qualitativa. Os dados da pesquisa 
foram coletados no período de agosto a outubro de 2018 e ocorreu na cidade de Ipaporanga, localizada no interior do Estado do Ceará. A cidade possui uma área territorial de 704,773 km² e uma população estimada de 11.593 habitantes (IBGE, 2019).

O estudo foi composto de uma pesquisa bibliográfica sobre três espécies nativas encontradas no município de Ipaporanga: o Juazeiro (Ziziphus joaseiro), o Mandacaru (Cereus jamacaru) e o Umbu-cajá (Spondia tuberosa). Posteriormente, houve a aplicação de um questionário, com viés etnobotânico, aos estudantes, funcionários e professores, visando uma amostragem com diversidade de conhecimentos e de faixa etária. Paralelamente ao questionário, foi utilizado um diário de bordo, no qual eram anotados os comentários que os entrevistados teciam com relação às perguntas.

Para a pesquisa bibliográfica sobre as espécies analisadas foram consultados livros, artigos, dissertações, cartilhas e folhetins que abordavam as três espécies em estudo, a fim de ampliar o conhecimento sobre cada uma delas. Em seguida foi elaborado o questionário etnobotânico, contendo 10 questões (Quadro 1), variando entre abertas e fechadas, com a finalidade de avaliar o nível de conhecimento que o público escolar detinha sobre as espécies nativas estudadas.

Nesta pesquisa participaram 30 sujeitos, sendo 10 alunos do $7^{\circ}$ ano do ensino fundamental de duas turmas distintas que estavam estudando conteúdos de botânica, 10 professores da área das ciências da natureza com ensino superior nessa área e 10 funcionários com funções diversas na instituição de ensino básico e com escolaridades distintas. A escolha dos sujeitos se deu a fim de proporcionar uma amostra de todo o público escolar que atua em conjunto na instituição escolhida. Em seguida foi realizada uma apresentação e contextualização dessas espécies nas aulas de ciências. Tal atividade aconteceu na única escola de ensino fundamental da zona urbana deste município, cuja escolha se sucedeu devido ao fácil acesso e à localização centralizada em Ipaporanga-CE. O questionário foi acompanhado do termo de consentimento livre e esclarecido para professores e funcionários e o termo de assentimento de estudantes para os alunos.

Quadro 1 - Questionário etnobotânico aplicado aos pesquisados. 


\begin{tabular}{|c|c|}
\hline $\begin{array}{l}\text { 1) Faixa etária: } \\
\text { ( ) } 13 \text { a } 29 \text { anos } \\
\text { ( ) } 30 \text { a } 39 \text { anos } \\
\text { ( ) } 40 \text { a } 49 \text { anos } \\
\text { ( ) } 50 \text { a } 59 \text { anos } \\
\text { ( ) } 60 \text { a } 69 \text { anos } \\
\text { ( ) acima de } 70 \text { anos } \\
\text { 2) Grau de instrução: } \\
\text { ( ) Analfabeto } \\
\text { ( ) Alfabetizado } \\
\text { ( ) Ensino Fundamental Incompleto } \\
\text { ( ) Ensino Fundamental Completo } \\
\text { ( ) Ensino Médio Incompleto } \\
\text { ( ) Ensino Médio Completo } \\
\text { ( ) Ensino Superior } \\
\text { 3) Você conhece as espécies nativas de sua } \\
\text { região? } \\
\text { (() Sim, Bem poucas } \\
\text { ( ) Sim, Algumas } \\
\text { ( ) Sim, Já ouviu falar } \\
\text { ( ) Não conheço nenhuma. } \\
\text { 4) Você já utilizou estas espécies nativas } \\
\text { para que finalidade? } \\
\text { ( ) Alimentação } \\
\text { ( ) Para fins medicinais } \\
\text { ( ) Para fabricação de alimentos } \\
\text { ( ) Outros }\end{array}$ & $\begin{array}{l}\text { 5) Você já utilizou o Juá, o mandacaru ou umbu } \\
\text { em sua alimentação ou para outros fins? } \\
\text { ( )Sim ( )Não } \\
\text { 6) Que outros frutos de nossa região você } \\
\text { costuma utilizar em seu dia a dia? } \\
\text { 7) Você cultiva alguma dessas espécies ou } \\
\text { outras espécies nativas em seu quintal? } \\
\text { ( ) Não, nunca cultivei } \\
\text { ( ) Não, mas já cultivei } \\
\text { ( ) Sim, cultivo há a algum tempo } \\
\text { ( ) Sim, cultivo há a pouco tempo } \\
\text { 8) Além do fruto, você já utilizou ou tem } \\
\text { conhecimento sobre a utilização de outras } \\
\text { partes destas espécies vegetais? } \\
\text { ( ) Sim, já utilizei as folhas ou a flores } \\
\text { ( ) Sim já utilizei o caule } \\
\text { ( ) Sim já utilizei a raiz } \\
\text { ( ) Não utilizei outras partes } \\
\text { 9) Você acha que essas espécies de frutas estão } \\
\text { desaparecendo da comunidade local? Por quê? } \\
\text { 10) Você acha importante a preservação dessas } \\
\text { espécies nativas? Por quê? }\end{array}$ \\
\hline
\end{tabular}

Fonte: elaborado pelos autores (2018).

Após a aplicação do questionário, os dados coletados foram reunidos e tabulados. Estes foram analisados conforme os postulados da Análise de Conteúdo de Bardin (2011), realizando uma comparação com o que foi encontrado na pesquisa bibliográfica. Após a tabulação e comparação dos resultados, houve o planejamento de uma ação para apresentar os dados e reverter possíveis equívocos nas falas dos pesquisados. Assim, preparou-se um seminário com o tema do trabalho para apresentar nas aulas de ciências.

O seminário foi apresentado em duas turmas de $7^{\circ}$ ano do ensino fundamental II pelo fato da matriz curricular deste ano escolar contemplar o conteúdo de botânica e por estarem estudando o assunto no período da pesquisa. Em cada turma foi utilizado o tempo de duas aulas, de 50 min cada. Desta forma, a apresentação também foi realizada com o intuito de apresentar 
frutas mais próximas da realidade dos alunos, como uma forma de contextualizar as aulas de ciências.

A apresentação foi estruturada em duas etapas. De início foi realizada uma sondagem geral acerca do tema Plantas Nativas. Na segunda etapa foram apresentados os dados às turmas da pesquisa, para a partir daí promover a conscientização e contextualizar o assunto em questão.

\section{RESULTADOS E DISCUSSÃO}

O município onde foi realizada a pesquisa está imerso no domínio caatinga, contendo várias espécies vegetais nativas, que são conhecidas por várias denominações e utilizadas pela população local para diversos fins. Muitas delas nascem de forma espontânea e podem apresentar propriedades fitoterápicas, apesar de serem confundidas com ervas daninhas ou invasoras (CORDEIRO; FELIX, 2014).

A pesquisa teve como enfoque uma investigação do conhecimento etnobotânico do público de uma escola, através da aplicação de um questionário, com a finalidade de que os dados encontrados fossem utilizados como base de contextualização no ensino de ciências. Dentre os pesquisados, identificou-se que 14 possuíam idade entre 13 e 29 anos, enquanto 6 tinham entre 30 e 39 e 10 possuíam de 40 a 49 anos. Relacionado ao grau de instrução, 12 tinham formação em ensino superior completo, ao passo que junto aos 10 alunos, um total de 15 partícipes tinham ensino fundamental incompleto, enquanto 3 possuíam tal grau de instrução completo. De início serão apresentados os dados obtidos com o questionário e em seguida os dados obtidos com a apresentação do tema nas aulas de ciências.

\subsection{Análise do questionário etnobotânico}

As três primeiras perguntas do questionário foram utilizadas para caracterizar o público entrevistado e ajudar a discutir melhor os resultados. Sobre o conhecimento a respeito das espécies nativas, propostas na pesquisa (questão 3, quadro 1), foi constatado que 29 entrevistados possuíam algum conhecimento sobre essas espécies e, destes, 3 afirmaram que detinham pouco conhecimento. Os entrevistados que demonstraram ter um conhecimento a mais sobre espécies nativas eram, em sua maioria, professores e funcionários, com faixa etária acima de 30 anos. Alguns, além de escolher uma das opções, teceram ainda comentários sobre 
suas escolhas. Um deles afirmou ter tido um contato mais próximo com essas espécies durante a infância e a adolescência.

Outro ainda destacou que antes, devido ao atual município fazer parte da zona rural, essas espécies eram vistas mais facilmente. A parcela que mostrou pouco conhecimento era formada, em sua maioria, por alunos pesquisados que se enquadravam na faixa etária entre 13 e 29 anos. A escola onde a pesquisa foi realizada concentra, em sua maioria, alunos que residem na sede do munícipio, o que permite pensar que o baixo conhecimento se dá, possivelmente, pelo fato deles já terem nascido num meio urbano e mais desenvolvido, apesar de estarem inseridos no mesmo município que os professores e funcionários da escola, porém vivem numa realidade diferente da que os de maior faixa etária vivenciaram.

Na prática, a urbanização pode ser considerada como um fator decisivo que contribui para um conhecimento superficial sobre espécies nativas. Isso é perceptível ao observar que o público adulto traz consigo conhecimentos mais aprofundados que os alunos, adquiridos através de seus antepassados, sendo que hoje em dia pode-se considerar um fato raro esse aprimoramento de conhecimento para novas gerações, o que explica o conhecimento supérfluo do público, entre eles alunos adolescentes. Além disso, o contato das gerações anteriores com tais espécies era mais fácil, enquanto na atualidade não, visto as suas diminuições ao longo do tempo e a pouca explanação durante as aulas de ciências na escola.

Corroborando com esses achados, Scherer, Essi, Pinheiro (2015) apontam que os estudantes entrevistados, residentes na zona urbana, possuíam baixo conhecimento sobre espécies brasileiras, ao contrário de estudantes que se encontravam na zona rural, que tinham mais conhecimento sobre espécies nativas. Pode-se elencar vários fatores que contribuem para essa diferença de conhecimento, como por exemplo o desmatamento, como decorrência do crescimento das cidades, ou até mesmo o contato, pois se torna mais fácil encontrar espécies nativas em áreas ainda não urbanizadas do que em áreas urbanas.

Quando questionados quanto à utilização de espécies nativas (questão 4, quadro 1), as propriedades medicinais foram apontadas como o motivo de utilização por 23 entrevistados. Um dos entrevistados chegou a mencionar a importância do caráter medicinal dessas espécies como uma possibilidade de método alternativo de combate às enfermidades. Outro acrescentou a necessidade de se utilizar de meios naturais para sintomas mais simples, criticando, assim, o uso excessivo de medicamentos farmacêuticos. 
Esses métodos medicinais alternativos são comumente passados entre diversas gerações, bem como também são explicitados em aulas de ciências, fato este que contribui para a elevada taxa de utilização para fins medicinais. Esta situação vem de encontro com a pesquisa de Zeni et al. (2017), na qual os autores também apontaram que a maioria dos entrevistados utilizam espécies medicinais para fins terapêuticos, através de tratamentos caseiros. Os autores ainda discutem os dados obtidos pela Organização Mundial da Saúde (OMS) em que revelam que as plantas medicinais estão se tornando cada vez mais procuradas devido ao baixo custo.

Tais tipos de conhecimentos sobre a natureza, relacionados à cultura de um povo, foram repassados e reformulados através das gerações. Com base nesses tipos de conhecimentos, a sobrevivência dos seres humanos se tornou possível, já que esses saberes oportunizaram aos grupos humanos a capacidade de se adaptar ao meio ambiente e, de certa forma, de se relacionar com a natureza (TOLEDO; BARRERA-BASSOLS, 2015).

Ainda na mesma questão, torna-se importante destacar que alguns dos entrevistados optaram por mais de uma resposta. O uso das espécies nativas para a alimentação configurouse como a segunda opção mais citada pelos participantes. Cerca de 15 pessoas marcaram essa alternativa. Um total de 5 dos entrevistados, cuja faixa etária está acima de 30 anos, chegaram a destacar durante o preenchimento do questionário que já utilizaram espécies nativas para a alimentação, através do consumo in natura, porém não corriqueiramente. Muitos se alimentaram desses frutos ainda na infância, outros dificilmente se alimentam do fruto. Também foi citada a utilização de espécies nativas da região para a fabricação de alimentos derivados, como o preparo de sucos naturais e doces à base da fruta, no caso do umbu-cajá.

O mandacaru pode ser utilizado na fabricação de alimentos para o rebanho, para a alimentação de pássaros e sendo pouco consumido pelas pessoas. $\mathrm{O}$ fruto do juá foi citado mais em caráter medicinal, mas alguns também já mostraram ter consumido o fruto alguma vez. Ainda neste contexto, 2 participantes, após preencherem o questionário, comentaram sobre o consumo dessas plantas nativas para outros fins, como a utilização para o artesanato, no que se refere a espécies, como a carnaúba e demais palmeiras que são utilizadas para a fabricação de cestos e outros utensílios de palha. Além do fruto, citaram utilizar também o caule para a construção de moradias, dentre outras finalidades.

De acordo com os resultados, pode-se observar a importância de estudos com espécies nativas devido às inúmeras qualidades e utilidades dessas plantas que podem despertar e alavancar oportunidades de renda para a população local. Cada uma delas possui um potencial 
que pode ser explorado pela população não só na alimentação, como visto, mas também na parte cultural e artística, como o artesanato. Além disso, o conhecimento a respeito delas pode despertar o interesse na preservação. As finalidades nutricionais dessas espécies poderiam incrementar várias áreas do ensino de ciências na escola, por exemplo. Ademais as características de espécies e seus frutos seriam uma ótima opção para se trabalhar com as temáticas de botânica, nutrição humana, entre outros assuntos, os quais relacionam o ser humano com a natureza.

Sobre as três espécies nativas da região de estudo, o juá, o mandacaru e o umbu-cajá, questionou-se se os entrevistados já haviam utilizado alguma das três espécies para a alimentação ou para outros fins (questão 5, quadro 1). Dos sujeitos investigados, 18 participantes mostraram já ter utilizado algumas destas espécies, enquanto 11 apontaram nunca ter utilizado. Dentre as pessoas que responderam “sim”, alguns investigados comentaram já ter utilizado a fruta umbu-cajá, para a fabricação de sucos e para a alimentação da fruta in natura, sendo esta última a mais utilizada dentre as três. O fruto do umbuzeiro é muito apreciado na região Nordeste, podendo ser consumido naturalmente, misturado ao leite ou na fabricação e produção de diversos tipos de doces. Sendo uma espécie nativa, o umbuzeiro tem certa resistência a grandes períodos de seca, que são contornados pela presença de raízes do tipo tuberosas que permitem esta adaptação à espécie (SILVA et al., 2012).

A segunda fruta dita mais usada foi o juá, cuja utilização para tratamento odontológico foi citada por um dos entrevistados. $\mathrm{O}$ entrevistado contou que, quando criança, a fruta já era utilizada por sua mãe que fabricava uma pasta natural com a polpa da fruta adicionada com menta e que há pouco tempo utilizou a mesma pasta para o tratamento de saúde bucal por cerca de 6 meses. Este fato nos comprova que os saberes acerca dessas espécies são utilizados entre as diversas gerações, sendo mais fortes em épocas passadas. Nota-se que o conhecimento desta propriedade medicinal do fruto do juá não é uma descoberta recente, mas são conhecimentos que ao longo dos anos atestam sua grande eficiência no tratamento de saúde bucal, o que o favorece como base para medicamentos odontológicos, como aponta a pesquisa de Araújo et al. (2017).

Essas propriedades poderiam ser aproveitadas e apresentadas ao público escolar não só em palestras de saúde bucal ou em campanhas sobre higienização dos dentes, mostrando também o contexto histórico e a evolução até o creme dental atual, mas poderia se tornar uma rica abordagem para o ensino de ciências em todas as modalidades e níveis de ensino. Isso 
acontece ao observar que os sujeitos escolares possuem saberes prévios referentes às plantas nativas, o que favorece o ensino da caracterização e dos benefícios destas para a sociedade.

Portanto, as práticas pedagógicas científicas, enriquecidas com o uso das plantas pelas comunidades, tornam-se uma metodologia eficaz e transforma o ensino de botânica mais atrativo, bem como proporcionam a interação e apropriação de conhecimento sobre o uso das espécies (LUBINI; GÜLLICH; SCHEID, 2015).

O Mandacaru possui ainda caráter medicinal, apesar dessa propriedade ser pouco conhecida. Acredita-se que tal planta tenha ação benéfica em doenças cardíacas, atribuída à presença da tiramina, substância responsável pela atividade cardiotônica. Importa acrescentar que todas as partes da planta, as quais incluem seu fruto, podem ser utilizadas no combate de doenças respiratórias, como bronquites e tosses (DAVET et al., 2009).

Quando questionados acerca de outras espécies que já utilizaram ou cultivaram (questão 6, quadro 1), os entrevistados em geral, que demonstraram conhecer alguma espécie nativa, elencaram diversas destas espécies que já cultivaram. Os entrevistados do bloco de professores e funcionários citaram espécies como o maracujá do mato (Passiflora cincinnata), pitomba (Talisia esculenta), que normalmente são dificilmente vistas no meio urbano. Os pesquisados do bloco de alunos apontaram espécies mais comuns ao dia-a-dia deles, como a seriguela (Spondias purpúrea) e o caju (Anacardium occidentale).

Provavelmente, a citação dessas espécies leva em conta o fato delas estarem entre as mais conhecidas na região onde os alunos residem. Interessante notar que os investigados, em geral, não distinguem bem quais espécies são nativas e quais são oriundas de outros locais. Tal diferenciação é um dos pontos que podem ser levantados no ensino desta temática na educação básica, pois incentivará a valorização das espécies nativas entre os sujeitos.

Quando questionados se cultivam ou se já cultivaram espécies vegetais nativas em sua residência atual (questão 7), 16 participantes afirmaram nunca ter cultivado alguma espécie nativa. O baixo número de cultivo pode ser devido à baixa valorização destas espécies atualmente. A procura por frutas de outras regiões e o consumo de espécies tradicionais na alimentação da população também pode ter um papel fundamental nesse número reduzido de cultivo. Outra razão para a baixa taxa de cultivo pode estar relacionada ao longo tempo de crescimento que estas espécies precisam até formarem os primeiros frutos, o que, com a urbanização, facilitou o acesso destes alimentos industrializados nos supermercados. Observou- 
se que as espécies cultivadas, em sua maioria, correspondem a espécies de outros locais, que comumente são encontradas nas frutarias, mercearias e demais locais de compra e vendas de frutas. Quanto aos alunos entrevistados, muitas dessas frutas mais comuns não nativas, são também apontadas como exemplos nas aulas, nos livros didáticos e também são utilizadas na merenda escolar.

Ao serem indagados sobre a utilização de outras partes de plantas nativas além do fruto (questão 8, quadro 1), novamente o número de entrevistados que nunca utilizaram foi bem considerável, 8 pessoas efetivaram tal afirmação. Isso também pode ser explicado por falta de informações a respeito das propriedades, pois este percentual corresponde aos estudantes e muitos deles não têm conhecimento ou convivência com essas plantas. Os entrevistados que possuíam um certo domínio sobre o uso dessas plantas apontaram o caule como a parte mais utilizada. Ao passo que selecionavam a opção, mencionaram já terem usado a casca do caule de algumas espécies nativas para diversos fins, provavelmente era bastante utilizado na região na construção de telhados, cercas e portas. Moradias denominadas "casas de taipa" podem explicar esse dado.

Ainda sobre a questão 8, o uso de folhas e flores também foi, em seguida, apontado pelos entrevistados que mencionaram o uso através de chás, sendo para sintomas simples ou para tratamentos mais longos de algumas enfermidades. A raiz foi mostrada como a parte menos utilizada. A pesquisa apontou caule e folha como as principais partes utilizadas, ao contrário de outros lugares do país onde as folhas ocupam o primeiro lugar e a casca ocupa o segundo lugar, como afirma a pesquisa de Ribeiro et al. (2014), que apontou a folha como a parte mais utilizada. A partir destes dados, observa-se o uso de diversas partes das plantas, possibilitando maior contato e aproveitamento das suas constituições.

Quando questionados se as espécies nativas estavam desaparecendo da paisagem da região (questão 9, quadro 1), apenas 3 dos entrevistados afirmaram que não. $\mathrm{Na}$ opinião da maioria dos pesquisados, os que disseram possuir conhecimento concordaram que as espécies nativas estão cada vez mais difíceis de serem vistas. Os participantes da pesquisa apontaram várias razões para este acontecimento. Em geral, os estudantes indicaram as queimadas como principal fator, o que demonstra reconhecimento pelos alunos quanto ao malefício desta prática às plantas. Outros agravantes, como desmatamento, extração de madeira, urbanização, períodos de estiagem e a própria falta de conhecimento das utilidades, foram citados como contribuintes para tal acontecimento.

Recebido em: $27 / 01 / 2021$

Aceite em: 20/08/2021 
Reflexões sobre esses fatores que contribuem para esse desaparecimento de espécies também podem se tornar temas de debates e esclarecimentos em sala de aula. $\mathrm{O}$ aluno, bem como o professor, pode utilizar o período das aulas de ciências para também provocar uma conscientização em outras pessoas. A prática do ensino deve justamente estimular para que os alunos absorvam essas informações, compreendam a importância e passem também a conscientizar outras pessoas não só no espaço da sala de aula, mas além do ambiente escolar.

É notório que a cada dia as espécies nativas no município estão se tornando mais escassas, principalmente no meio urbano, onde raramente é possível encontrar algum exemplar. No meio rural, apesar de encontrar com mais frequência, também não são tão visíveis em ambientes próximos a residências. Em geral, são mais facilmente encontradas em regiões mais afastadas da presença humana.

Andreoli et al. (2014) alertam que mesmo o Brasil sendo rico em biodiversidade, muitas destas espécies vegetais estão desaparecendo do cenário em que vivemos devido à ocupação humana de forma desastrosa, bem como aos impactos ambientais que contribuem para que isso aconteça, dos quais podemos citar a degradação dos ecossistemas, que afetam diretamente a fauna e a flora, bem como contribuem para o desaparecimento das espécies.

Quanto à importância da preservação das espécies nativas (questão 10, quadro 1), apenas 1 pessoa não considerou importante a preservação das mesmas, enquanto 29 afirmaram achar importante a preservação. Dentre as razões para o cuidado com essas espécies, os entrevistados justificaram através das variadas utilidades, dentre elas a manutenção do ecossistema e o equilíbrio da flora local.

Andreoli et al. (2014) ressaltam que apesar de a grande parte perceber a importância de se preservar, ainda há uma minoria de pessoas que não reconhecem a importância da preservação e, quando se olha o país como um todo, observa-se que é bem maior o número de pessoas que não reconhecem a importância de espécies para a vida dos animais e seres humanos, no que diz respeito à qualidade de vida e ao equilíbrio e manutenção da biodiversidade. $\mathrm{O}$ interessante é que o contexto histórico dessas espécies também foi visto como fator para a preservação, uma vez que a comunidade escolar apontou como sendo importante que as novas gerações conheçam essas espécies que fazem parte de patrimônio natural e se relacionam com a sua cultura e a sua história. 
Propostas também foram apontadas para a preservação dessas espécies. Uma das medidas seria ampliar o conhecimento sobre essas espécies e aprender a conviver com elas, fazer um resgate, evitando uma possível extinção em um futuro próximo. Medeiros, Medeiros e Brito (2017), em sua pesquisa, afirmam que é possível conviver adequadamente com espécies de clima semiárido, como as espécies nativas, mas que para isso é necessário conhecimento sobre o tema.

A partir destas análises, verifica-se o quão preciso é disseminar saberes científicos para preservação das plantas nativas. Isso decorre devido ao encontro de sujeitos que ainda não consideram necessário preservar tais plantas, no entanto as utilizam para diversas atividades humanas. Por isso, torna-se necessário sensibilizar a população para que haja maior reconhecimento de seus usos durante as atividades rotineiras. Desta forma, o ensino de botânica, dentro da área de ciências da natureza, ganha destaque como disseminador das relações humanas com as plantas do contexto local. Em continuidade à presente pesquisa científica, realizou-se uma atividade de intervenção, em formato de seminário, aos alunos. Esta ação foi melhor descrita no subtópico a seguir.

\subsection{Análise do seminário apresentado na escola}

Com base nos dados do subtópico anterior, verifica-se o panorama de saberes dos sujeitos investigados, além das possibilidades de abordagens propiciadas pelo ensino de ciências ao promover as temáticas de botânica. Portanto, após os dados coletados na aplicação do questionário, foi feita uma apresentação dialogada sobre a temática de frutas nativas nas aulas de ciências. Os alunos tiveram a oportunidade de compreender a definição e as classificações das frutas. Ao longo dessa explicação, notaram-se algumas dificuldades de compreender os termos científicos e a definição do que seria uma fruta, o que corresponde a uma das dificuldades do ensino de botânica, no qual o entendimento dos termos científicos são desafios pelos alunos.

Ao notar a dificuldade de conceituação pelos alunos, realizou-se um diálogo sobre a definição geral das frutas, com o intento de compreensão exitosa pelos alunos, que inicialmente associavam o termo fruta a algo comestível e após a explicação passaram a compreender o conceito a partir de sua originalidade do ovário. Ainda dentro deste contexto de conceituações, questionou-se aos partícipes da aula sobre o que eles entenderiam do termo "nativo", associando 
com as frutas. Relacionando o solicitado com as frutas nativas, os alunos responderam de forma satisfatória ao questionamento do que significava o termo "nativo" e complementaram se já tinham ouvido falar e onde tinham ouvido. Eles responderam como nativo sendo algo relativo a um determinado local e relacionaram a terra natal.

Após esse processo de definições explicou-se sobre a classificação de frutas. Percebeu-se uma maior facilidade ao classificar frutas mais comuns do cotidiano deles do que as nativas. Porém ao apresentar os exemplos de frutas nativas, seguido da visualização de imagens e o conhecimento das suas características, os alunos souberam classificá-las facilmente, aprimorando o que já sabiam e confirmando o quão é importante a contextualização para a aprendizagem.

Uma possível explicação para este fato seria a apresentação ter sido mais contextualizada, utilizando exemplos e principalmente imagens mais próximas do cotidiano em que o aluno vive, que, muitas vezes, não são abordados pelo livro didático e dificultam a aprendizagem. Por isso, a adição de exemplos locais facilita a aprendizagem referente às plantas, promovendo melhor o ensino de ciências.

A prática de contextualização oferece justamente ao aluno a oportunidade de expressar o seu conhecimento prévio sobre o assunto, propiciando de certa forma um diálogo com outras formas de saberes. Isso proporciona que novos olhares acerca do tema estudado se tornem um elo com outras áreas afins (LUCA et al. 2018).

Além das espécies nativas abordadas neste trabalho, outras mais comuns foram apresentadas para os discentes, como a seriguela, caju, pitomba e a carnaúba, bastante conhecidos na região. Os alunos interagiram muito, destacando e contando exemplos de informações que já detinham sobre elas, que faziam parte do contexto deles. Em relação à seriguela, foram apresentadas as diversas finalidades que o fruto possui, o que fez com que os alunos demonstrassem curiosidade em saber o processo de preparo do suco por conta da sua característica. A partir disso, explicou-se o modo de preparo e, nesse momento, a professora também explicou outra forma que utilizava em casa. Foi perceptível como os alunos mostram uma melhor participação quando a abordagem é feita de forma contextualizada, pois envolve os discentes em atividades fora dos espaços escolares.

Quanto à carnaúba, foram apontados exemplos de utilização e os próprios alunos mencionaram alguns deles. A vassoura e o chapéu de palha foram os produtos sobre os quais 
os alunos demonstraram conhecimento e que eram feitos a partir da carnaúba. Outras aplicações foram explicitadas, como o uso da cera de carnaúba para a confecção de velas e cosméticos, fato que causou surpresa para os alunos. Isso pode ter ocorrido devido aos alunos desconhecerem essas utilizações na indústria de cosméticos, justamente devido ao fato dessas espécies não serem muito abordadas nos materiais didáticos. E por conviverem mais de perto com a utilização da palha, por meio do artesanato, mostraram conhecer apenas a utilização a base dela.

As atribuições mais mencionadas do caju foram: preparo de sucos, preparo de doces, o consumo da castanha e a produção da popular "cachaça do caju". Os estudantes também demonstraram curiosidade sobre o preparo dessa bebida. Muitos apontaram já terem visto seus pais preparando, outros mencionaram o fato de como o caju crescia dentro da garrafa. As indagações dos alunos foram refletidas com eles para melhor internalização dos apontamentos levantados, o que permite uma aprendizagem em ciências mais contextualizada e associada às suas vivências.

As três espécies nativas estudadas neste trabalho também foram apresentadas. No percurso de exposição, os alunos eram questionados acerca de cada uma. $\mathrm{O}$ interessante foi ter notado que eles já conseguiam classificar cada fruto nativo de acordo com o critério de classificação simples. Com foco nos frutos juá, mandacaru e umbu-cajá, o mandacaru foi elencado como o mais conhecido. Os alunos comentaram que já teriam visto essa espécie nas estradas, zona rural e até mesmo na casa dos avós e em jardins de outras residências, o que pode ser resultado do grande uso do mandacaru como planta ornamental típica do semiárido.

$\mathrm{Na}$ apresentação ainda foram abordadas pesquisas mais atuais na qual o fruto dessa espécie vem sendo usado para o preparo de doces, sacolés e outras guloseimas. Também foi destacada a questão de o mandacaru ser uma espécie com folhas modificadas em espinhos, para reduzir a perda de água, atuando também como proteção contra animais herbívoros. Diante da explicação, os alunos compreenderam o porquê dessa espécie sempre se manter verde e com o caule rico em água.

De acordo com Tavares et al. (2016), cremes e outros doces feitos a partir do mandacaru foram em grande parte aprovados pelo público. Uma pequena parcela afirma não gostar dessas iguarias, o que deve ser explicado devido à casca também ir junto à polpa do fruto, o que pode ter ocasionado o sabor meio amargo e a coloração mais escura nesses alimentos. Mas o que se 
pôde notar foi que, em geral, teve boa aceitabilidade e consiste numa alternativa futura de grande potencial de renda para as famílias.

O umbu-cajá, por ser mais comum nas localidades da zona rural do município, foi apontado como conhecido apenas por alguns alunos, inclusive um deles relatou residir numa dessas localidades e que em sua casa tem uma umbu-cajazeira. Entretanto, o juá, apesar de uma minoria conhecer, chamou atenção deles pelo fato dessa fruta ser usada para tratamentos odontológicos e como creme dental em décadas atrás.

Com base na atividade realizada, observa-se uma dialogicidade entre o professor e os alunos para promoção dos assuntos de plantas nativas. A associação destas plantas com a realidade proporcionou o esclarecimento de dúvidas e o aprofundamento de bases científicas essenciais na disseminação do conhecimento. Ao final do seminário, foi feita uma explanação se ele teria ajudado e facilitado a construção do conhecimento.

Os alunos afirmaram que a metodologia tinha sido muito favorável e a explicação foi atrativa. Eles até mesmo usaram como exemplo o fato de o livro didático não ser tão chamativo e não contemplar assuntos mais próximos deles. Esse posicionamento dos alunos revela a necessidade da contextualização nas aulas de ciências, contemplando a realidade de cada local. Por isso, há a necessidade de renovação da prática docente para aprimoramento desses recursos e materiais didáticos, procurando sempre mais contextualizar os conteúdos durante as aulas.

Apesar dos desafios existentes, quanto às abordagens presentes nos livros didáticos de ciências, percebe-se que houve uma melhora neste sentido ao longo dos anos. É o que aponta a pesquisa de Leopoldo e Bastos (2018), que identificaram que o os aspectos curriculares dos livros mudaram ao longo do tempo, bem como observaram os reflexos deste efeito no ensino de botânica.

Ao professor é atribuída a capacidade de inovar e variar suas atividades didáticopedagógicas (BONATTO et al., 2012), porém a proposta da contextualização é ainda pouco praticada, pois os docentes sentem a carência de suportes para desenvolverem suas aulas. Faltam ainda materiais que contemplem o contexto e a realidade do semiárido (NEGREIROS; CAMPANI, 2012).

A contextualização de espécies nativas nas aulas de ciências pode vir a ser um grande atrativo para os alunos. Ao apresentar o seminário temático, não só os alunos, mas também o professor notou a importância dessas espécies para a região, bem como observaram uma maior 
interação na aula. Tudo isso demonstra a relevância de trabalhos realizados na perspectiva descrita no presente artigo.

\section{CONSIDERAÇÕES FINAIS}

O estudo de espécies vegetais nativas é de fundamental importância para o ensino e a aprendizagem nas regiões onde estas espécies se encontram. Estudar mais a fundo as espécies nativas, bem como também entender as relações que elas mantêm com a escola e com o ambiente onde se encontram, proporciona uma maior valorização da flora local, além de facilitar e despertar diversos modos, ideias e propostas para uma melhor contextualização de conteúdos em sala de aula.

Houve a constatação que o público escolar reconhece, ou ao menos ouviu falar das espécies vegetais nativas, porém sendo perceptível a escassez de informações e conhecimentos sobre as propriedades e benefícios que estas espécies possuem. Quando é levada em consideração a questão da utilização dessas espécies, existe uma parcela que ainda as utiliza para algum fim. No entanto, foi observada uma diminuição nessa taxa de utilização, mediante o fato de plantas nativas estarem sendo substituídas por plantas tradicionais de outras regiões. É justamente a disseminação do conhecimento acerca dos benefícios oferecidos pelas nativas que podem modificar este quadro e ampliar o cultivo nessa região.

Quando se lançou o olhar sobre o estudo dessas espécies em sala de aula, através da apresentação de um seminário, foi constatada a extrema necessidade da contextualização no ambiente escolar. A parcela do público escolar, formada em sua maioria pelos alunos, almeja aulas mais voltadas para sua realidade, para o seu dia a dia, para o seu lugar, como também os professores sentem a necessidade de difundir técnicas, disseminar e formular outras maneiras e ideias de como contextualizar suas aulas. O seminário aproximou os estudantes do seu cotidiano, além de proporcionar ao aluno e ao professor o conhecimento necessário para despertar a valorização dessas espécies.

Compreende-se ainda que a amostra de entrevistados do grupo de professores e funcionários traz, mesmo que de forma tímida, conhecimentos sobre espécies nativas em estudo, adquiridos pelos seus antepassados. Esse repasse hereditário de conhecimentos populares vem desaparecendo entre as atuais gerações, como observamos nas respostas da amostra representada por alunos. Portanto, o ensino de ciências colabora na disseminação de assuntos acerca das plantas nativas, promovendo com êxito os temas de botânica. 


\section{REFERÊNCIAS}

AGOSTINHO, A. B. Etnobotânica: conhecimentos tradicional e científico. FLOVETBoletim do Grupo de Pesquisa da Flora, Vegetação e Etnobotânica, v. 1, n. 8, p. 60-67, 2016.

ANDREOLI, C. V.; ANDREOLI, F. N.; PICCININI, C.; SANCHES, A. L. Biodiversidade: a importância da preservação ambiental para manutenção da riqueza e equilíbrio dos ecossistemas. Coleção Agrinho, Curitiba: Kairós, 2014.

ARAÚJO, E. F.; ARAÚJO, W. F.; LIMA, E. T. A.; ARAÚJO, M. A.; MAGALHÃES, I. C.; LIMA, T. H.; PRADO, R. M. S. Atividade antimicrobiana do Ziziphus joazeiro martius: uma contribuição orgânica para a odontologia. Jornada Odontológica dos Acadêmicos da Católica, v. 2, n. 2, p. 1-7, 2017.

BARDIN, L. Análise de conteúdo. Lisboa: Edições 70: LDA, 2011.

BONATTO, A.; BARROS, C. R.; GEMELI, R. A.; LOPES, T. B.; FRISON, M. D. Interdisciplinaridade no ambiente escolar. In: Seminário em Educação da Região Sul, IX, 2012, Caxias do Sul. Anais... Rio de Grande do Sul, 2012.

CETAP, Frutas Nativas: alimentos locais, sabores e ingredientes especiais. Passo Fundo-RS, 2015. Disponível em: http://www.cetap.org.br/site/wpcontent/uploads/material/frutas_nativas-2015.pdf. Acesso em: 17/05/2020.

CORDEIRO, J. M. P.; FÉLIX, L. P. Conhecimento botânico medicinal sobre espécies vegetais nativas da caatinga e plantas espontâneas no agreste da Paraíba, Brasil. Revista Brasileira de Plantas Medicinais, v. 16, n. 3 suppl1, p. 685-692, 2014.

CRUZ, L. P.; JOAQUIM, W. M.; FURLAN, M. R. O estudo de plantas medicinais no ensino fundamental: uma possibilidade para o ensino da botânica. Revista Thesis, v. 7, n. 15, p. 7892, 2011.

DAVET, A.; VIRTUOSO, S.; DIAS, J. F. G.; MIGUEL, M. D.; OLIVEIRA, A. B.; MIGUEL, O. G. Atividade antibacteriana de Cereus jamacaru DC, Cactaceae. Revista brasileira de farmacognosia, v. 19, n. 2B, p. 561-564, 2009.

FREITAS, C. L. Uso terapêutico e religioso das ervas. Revista Caminhos-Revista de Ciências da Religião, v. 12, n. 1, p. 79-92, 2014.

HANAZAKI, N.; ZANK, S.; FONSECA-KRUEL, V. S.; SCHMIDT, I. S. Indigenous and traditional knowledge, sustainable harvest, and the long road ahead to reach the 2020 Global Strategy for Plant Conservation objectives. Rodriguesia, v. 69, n. 4, p. 1587-1601, 2018.

IBGE - Instituto Brasileiro de Geografia e Estatística. Panorama do Município de Ipaporanga. Disponível em: https://cidades.ibge.gov.br/brasil/ce/ipaporanga/panorama. Acesso em 17/08/2020.

KOHLER, M.; BRACK, P. Frutas nativas no Rio Grande do Sul: cultivando e valorizando a diversidade. Agriculturas, v. 3, n. 2, 2016.

Recebido em: $27 / 01 / 2021$

Aceite em: 20/08/2021 
LEITE, C.; FERNANDES, P.; MOURAZ, A. Contextualização curricular: princípios e práticas. Revista Interacções, n. 22, p. 1-5, 2012.

LEOPOLDO, L. D.; BASTOS, F. A pesquisa em Ensino de Botânica: contribuições e características da produção científica em periódicos. Revista Insignare Scientia-RIS, v. 1, n. 3, p. 1-21, 2018.

LUBINI, F.; GÜLLICH, R. I. C.; SCHEID, M. S. Conhecendo e identificando os diferentes tipos de raízes e caules das plantas angiospermas. In: CIECITEC, III, 2015, Santo Ângelo. Anais... Rio de Grande do Sul - RS, 2015.

LUCA, A. G.; SANTOS, S. A.; PINO, J. C. D.; PIZATTO, M. C. Experimentação contextualizada e interdisciplinar: uma proposta para o ensino de ciências. Revista Insignare Scientia-RIS, v. 1, n. 2, p. 1-21, 2018.

MEDEIROS, W. K. B.; MEDEIROS, W. I. B.; BRITO, M. C. D. Desafios e possibilidades da educação contextualizada: reflexões acerca da convivência com o semiárido. Revista Includere, v. 3, n. 1, p. 437-446, 2017.

NASCIMENTO, T. E.; COUTINHO, C. Metodologias ativas de aprendizagem e o ensino de Ciências. Revista Multiciência Online, v. 2, n. 3, p. 134-153, 2017.

NEGREIROS, J.; CAMPANI, A. Educação contextualizada para a convivência com o semiárido no sistema de ensino do município de Irauçuba-CE. In: Fórum Internacional de Pedagogia. Parnaíba. Anais... Parnaíba - PI, 2012.

NEGRI, T. C.; BERNI, P.; BRAZACA, S. Valor nutricional de frutas nativas e exóticas do Brasil. Biosaúde, v. 18, n. 2, p. 82-96, 2016.

RIBEIRO, D. A.; MACÊDO, D. G.; OLIVEIRA, L. G. S.; SARAIVA, M. E.; OLIVEIRA, S. F.; SOUZA, M. M. A.; MENEZES, I. R. A. Potencial terapêutico e uso de plantas medicinais em uma área de Caatinga no estado do Ceará, nordeste do Brasil. Revista Brasileira de Plantas Medicinais, v. 16, n. 4, p. 912-930, 2014.

RODRIGUES, B. A.; BORGES, A. T. O ensino de ciências por investigação: reconstrução histórica. In: Encontro de Pesquisa em Ensino de Física. Curitiba. Anais... Curitiba, 2016.

SCHERER, H. J.; ESSI, L.; PINHEIRO, D. K. O conhecimento da Biodiversidade: um estudo de caso com estudantes de graduação de uma universidade brasileira. Revista Monografias Ambientais, v. 14, n. 2, p. 49-58, 2015.

SILVA, C. M.; SILVA, C. I.; HRNCIR, M.; QUEIROZ, R.; FONSECA, V. L. I. Guia de plantas: visitadas por abelhas na caatinga. Fortaleza- CE, Fundação Brasil Cidadão, 2012.

TAVARES, D. L.; SOUSA, R. N. S.; RIBEIRO, S. S. L.; LUCENA, T. K. P.; LIMA, A. K. V. O. Aceitação de receitas de sobremesas elaboradas com fruto de mandacaru (Cereus jamacaru). In: Congresso Internacional da Diversidade do Semiárido, 1, 2016, Campina Grande. Anais... Campina Grande - PB, 2016.

Recebido em: $27 / 01 / 2021$

Aceite em: 20/08/2021 
TOLEDO, V. M.; BARRERA-BASSOLS, N. A memória biocultural: a importância ecológica das sabedorias tradicionais. Editora Expressão Popular, 2015.

ZENI, A. L. B.; PARISOTTO, A. V.; MATTOS, G.; HELENA, E. T. S. Utilização de plantas medicinais como remédio caseiro na Atenção Primária em Blumenau, Santa Catarina, Brasil. Ciência \& Saúde Coletiva, v. 22, n.8, p. 2703-2712, 2017. 